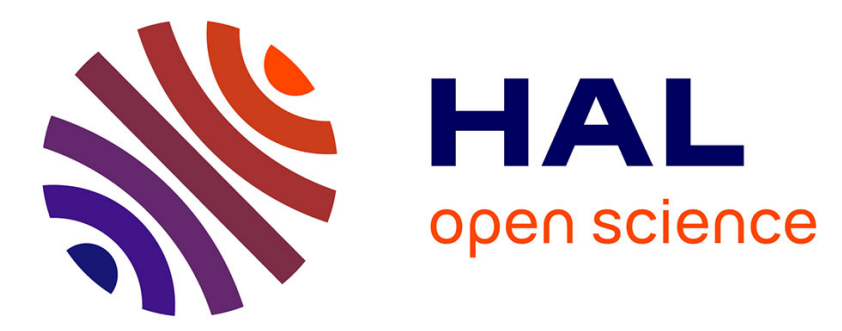

\title{
An event procedure management to support decision-makers in prospective and real-time project management
}

Vincent Robin, François Marmier, Séverine Sperandio, Didier Gourc

\section{To cite this version:}

Vincent Robin, François Marmier, Séverine Sperandio, Didier Gourc. An event procedure management to support decision-makers in prospective and real-time project management. 12th IFAC/IFIP/IFORS/IEA Symposium on Analysis, Design, and Evaluation of Human-Machine Systems, 2013, Las Vegas, United States. hal-00989557

\section{HAL Id: hal-00989557 \\ https://hal.science/hal-00989557}

Submitted on 5 Dec 2018

HAL is a multi-disciplinary open access archive for the deposit and dissemination of scientific research documents, whether they are published or not. The documents may come from teaching and research institutions in France or abroad, or from public or private research centers.
L'archive ouverte pluridisciplinaire HAL, est destinée au dépôt et à la diffusion de documents scientifiques de niveau recherche, publiés ou non, émanant des établissements d'enseignement et de recherche français ou étrangers, des laboratoires publics ou privés. 


\title{
An event procedure management to support decision-makers in prospective and real-time project management
}

\author{
V. ROBIN*. F. MARMIER**, S. SPERANDIO*, D. GOURC** \\ *IMS Laboratory - UMR CNRS 5218 - University of Bordeaux \\ France (e-mail: first name.surname@ims-bordeaux.fr) \\ ** Centre Génie Industriel - Ecole des mines d'Albi-Carmaux 81013 ALBI CEDEX 9, France \\ (e-mail: first name.surname@ mines-albi.fr)
}

\begin{abstract}
Companies are faced with a more and more demanding market in a context in constant evolution. Their ability to win contracts and bring in innovative projects is often based on some specific resources and ability to use them by considering their evolution. So project managers must reliably know the resource requirements and evolution over the projects timelines. However, few guides, books or studies on project management deal with these aspects in risky projects. The aim of this article consist in presenting the decision support system we have implemented to help project managers. The various feasible solutions are generated and modeled in a decision tree, which is connected with a model for scenario evaluation. The manager is then able to evaluate, compare and choose the best way to control the level of project risk and feasibility of the planning. Finally, a study illustrates the complexity of the decision making problem and validates our approach.
\end{abstract}

Keywords: Decision support system, project planning, resource availability, risk management

\section{INTRODUCTION}

Coordination and control of engineering design are part of a global approach for the development of new products which implies the need to identify the different situations occurring during the design process and the adequate resources to satisfy design objectives. In design project management, the control of the progress of design process can be defined as the understanding of existing design situations (in the real world) in order to evaluate them and take decisions that will modify and improve the future process, according to design objectives given by customer specifications or issued from the company strategy. So, management of design projects is a problem of decision-making to support designers in their activities (Girard, 2004) in order for them to achieve an objective in a specific context. This specific context could have an influence on the project and refers to the environment of the enterprise (society, market, subcontractors, etc.) but also to its organization (Robin, 2010) (1, figure 1). Influences of the context affect each entity of the organization and consequently oblige to adopt a multi-level project management adapted to each decisionmaker at each decision-level (2, figure 1) in order to provide to each project manager a set of information representative of the real state of design situation. All the information has to be synchronized for each project in the organization to ensure coherence of the project management (3, figure 1). Information has also to be continuously defined and characterized to permit an efficient decision-making during the project progress (4, figure 1). It's possible only if each information flow, for each project, is traced analyzed and exploited to follow-up their progress (5, figure 1).

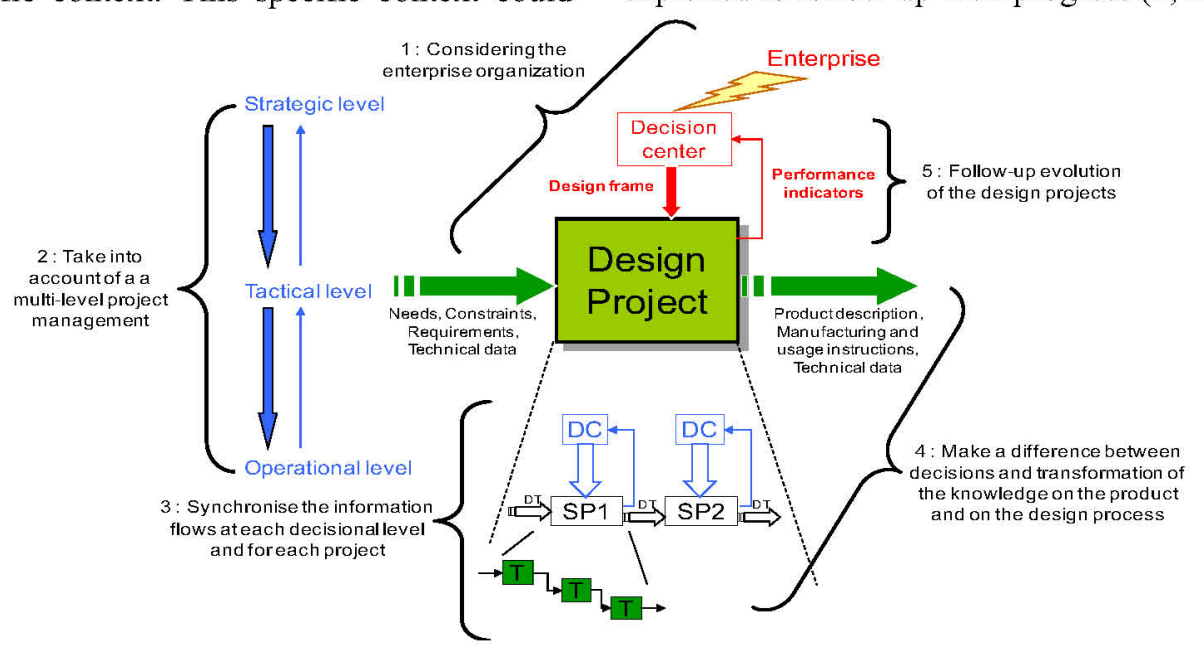

Fig. 1. Coordination of design project. 
In this paper we present models to identify, analyze and anticipate influences and impacts of each transformation in the system on the progress of the project. In the first section, we focus on the conceptual vision of system management to permit project management. We point out the fact that an event procedure is necessary to anticipate and respond to event that could have a more or less important disturbance on the system and consequently on the project. Second and third sections put in evidence all the models that have to be considered to take into account most of the elements and associated possible events influencing progress of projects.

\section{MANAGING SYSTEM TO MANAGE PROJECTS: CONCEPTUAL POSTIONING}

Control of the design system and design project management oblige to be able to understand and evaluate the design process, in particular the activities which make it up but also the context of the design. Thus, the evaluation of the design must propose a whole of elements of measurement, identified thanks to a model of the system, to provide relevant information to ensure a coherent decision-making in comparison with the real state of the system. Difficulty will be in the modeling of the system for its evaluation. Sperandio et al. (2007) believed that complex system analysis refers to:

- A functional point of view, i.e. the description of system functionality and behavior. System functionality concerns the purpose of the processes performed by the system, and system behavior results from flow control within the system (Vernadat, 1996).

- An ontological point of view, i.e. the description of resources used (human or technical), materials and information, and related control structures.

- A genetic point of view, which renders system evolutions and development.

Consequently, Sperandio et al. (2004) developed a modeling approach which is in line with these concepts. Its aim is to provide analysts with the appropriate view of a production system, depending on the depth of reengineering to be performed, from initial design to structural evolutions or breakthroughs. The modeling methodology is based on a global representation of the system life-cycle (Figure 2). The modeling process is made of five steps: (0) initialization, (1) set-up of a functional model, (2) elaboration of an organic model, (3) set-up of an operating - or operational - model, (4) definition of an event management procedure.

Model initialization is the first construction of system's view, definitely assumed to be functional to make the role of processes ensured by the system explicit. Hence, the aim of the functional model is to situate the enterprise (system) within its environment in order to understand the relations with its different partners such as identifying the constraints and degrees of freedom of decision making. Any strategic specificity should be captured. The organic view depicts the physical organization and resources which achieve the functions previously identified. Finally, the operational view stipulates the ways the organic system is exploited.

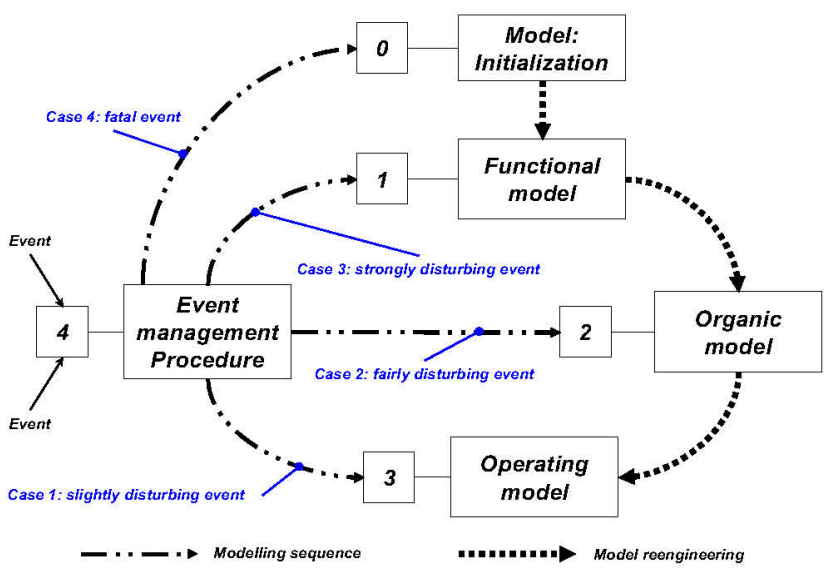

Fig. 2. Coordination of design project.

Along the system life-cycle, the appropriate models have to be used individually or sequentially to support reengineering analysis. The modeling trajectory is context-dependent and should be managed in accordance to evolution of system. An event management procedure is consequently necessary to take into account the various events coming from environment of system which trigger the evolution according to strategy of enterprise. Such events (eventually called disturbances) can be planned or unexpected, from external or internal origin, linked to market trends, eruption of new technologies, strategic or capitalistic decisions, etc. An event can be considered as:

- Slightly disturbing the current system if it has no impact on its structure (case 1, Figure 2). Such an event leads to a operational reengineering;

- Fairly disturbing if it acts upon the organic definition of the system, without modifying its functionality (case 2, Figure 2). Such an event leads to an organic reengineering;

- Strongly disturbing if it requires strategic system adjustments (case 3, Figure 2) impacting its functional characteristics. Such an event leads to a functional reengineering;

- Fatal if it makes the system obsolete (case 4, Figure 2) and leads to a dismantlement or full reengineering.

The use of such a system life-cycle modeling allows identifying the different types of design (functional, organic or operational design tasks) susceptible to punctuate the improvement process of an enterprise. At each sufficiently significant environmental modification being able to impact the system, or at each internal dysfunction considered to be critical, there is disturbance and a reorganization of the system is essential. Reengineering of the system could go from a simple adjustment of the operational realization of the system to a significant modification impacting its functions. The broader they are, the more the reengineering will take time. The whole of the modifications carried out on the system makes it possible to adapt the system to its environment and also increases its global performances. 
To be efficient the event management procedure has to provide decision-makers elements to anticipate an event and its impacts (prospective) and also to be reactive when an event appears (real-time project management). So, the system life-cycle modeling described in this section is too conceptual to be really operational. Next sections present a more precise decomposition of the functional, organic and operational models of the system and the use of a risk management approach to allow decision-maker managing design projects by anticipation and in real-time.

\section{MODELLING THE SYSTEM AND ITS ENVIRONMENT TO MANAGE ITS EVOLUTION}

To make appear all the relationships between the different levels of decision-making, we have to define each entity of the system and their interactions. The system regroups many projects, is composed with many teams, many actors, many resources. Moreover, in the system, projects begin and finish at different times, teams are created according to the needs of collaborations, actors take part of the project for specific activities, they could leave the enterprise, etc. In a nutshell, all these entities of the system and their own lifecycle have to be considered to understand the current and the possible evolutions of the system. So, we proposed to decompose the system by considering the enterprise, the design system and the actors which are essential to achieve project. The choice of the actor as smallest entity is justified by the fact that an actor is affected to projects, he works alone or in a team and he is in the design system, in the enterprise or in the other enterprises of the network. So, by focusing on the actor and factors influencing his evolution helps us to obtain a precise level of description of the factors impacting the design system and the enterprise. To take into account of the evolution of the system, we adopt a temporal view considering specific entities lifecycles.

\subsection{Focus on the actor in the design system}

In the context of extended enterprise, actors could be implied in the design project or not, could be in the design system or not, in the enterprise or not but they are compulsorily in the network of enterprises. The customers and the society have also to be taken into account regarding to their influences on the design product evolution (Boztepe, 2007). Factors influencing design performance concern in one hand the actor's activities and on the other hand the actor's context of evolution. These activities have to be analyzed regarding to the product, the process and the organizational viewpoints. The product view permits to show the actor's influence on the product. The models manipulated by the actor could be product or service models (designers), process or activity models (co-coordinators) or different kind of models (enterprise modeling, etc.) depending on the actor's attributions in a project. These models and their evolution have an interest only if we capitalized also the context in which they evolve. That obliges to consider the activities that bring the model evolution (process view) and the project associated to these activities (organizational view). Considering evolution of these models permits to define the real and possible actor's actions on the models (Gonnet, 2007). Models help to know what the actor has done, what he/she is doing and what he will be able to do on the product, in a given process and organization (Patanakul, 2008) that describe the actor's context of work. To specify the actor's context of evolution, we describe aspects from the actor himself to the system in which he has to work (figure 3). Some factors concerns actor's personal aspects and state of mind to help decision-maker understanding the actor to adapt his management style (Yang, 2008). Far from personality, actor's knowledge is also a performance determinant. If we identify what an actor knows, what he has to know and how he uses his knowledge, we are able to provide to him tools, methodologies, physical supports or training courses to achieve properly his tasks and to increase its self-esteem. Finally, to express his personality and his knowledge, actor must be in "good conditions". Consequently, we have to trace his internal and external relationships to identify his "autoorganization" and to create a favorable collaborative context of work (Girard, 2006). All these factors contribute to help decision-maker to optimize his management in the current projects and the future projects.

\subsection{The design system in the company}

Factors impacting performance of the design system are an aggregated vision of the lower description level (actor viewpoint). Managing information about each actor of the design allows building a global view of the design system. The partial product models of each actor designing this product are part of a more global product model in the design system. The aggregation of models of the actors' activities permits to obtain a global vision of the design process model. And all the processes are parts of the design projects which are organized in the design system. These elements are local performance factors for the design system. Internal and external resources, knowledge are identified too. Internal and external interactions between these elements contribute to make evolve the model of the design system and favor performance of design process (Chang, 2008). All these factors evolve with their own lifecycle and contribute to ensure performance of design (Hicks, 2002).

\subsection{The design system in the company}

Actors' evolution and evolution of the design system are also influenced by the enterprise, the network of enterprises and their interdependencies. The design actors, the design system are described and we focus here on the interactions between them, the company and the network of enterprises. Factors influencing design project at a strategic level have to be identified. That obliges to enlarge the notion of "project". Projects not only concern design project. Projects of the company may be financial or investment projects, expansion projects, partnerships projects (find new industrial partners), etc. A decision in one of these projects could affect design projects and could modify their evolution. Many processes composed these projects and could also impact the design. The results of these processes (products) could change the design product evolution. Consequently, the local performance determinants concern these projects regarding to the product, process and organizational viewpoints and the global determinants describe the enterprise on the whole. 
These factors help decision-makers at a strategic decisional level to know the situation of the company in term of resources' availability and capabilities, knowledge of the company (Chen, 2009), internal and external organization and its possible evolution (Chen, 2008). Before the beginning of the project he could identify event according to each element of the models and estimate risk and probability associated to then (failure of a resource, problem with subcontractor, delay increasing, etc.). He is able to obtain different scenarios to manage project according probability apparition of each event. Thanks to such scenarios he could anticipate an event and/or reduce the risk of its apparition. During the project, he/she could estimate influences of his/her decisions and choose the better scenario if an event appears. Next section presents the risk management approach used to exploit modeling elements of the system to obtain scenario helping decision-makers.

\section{MANAGING EVENTS FOR PROSPECTIVE AND REAL-TIME PROJECT MANAGEMENT}

In a project context, a risk may introduce different modifications or events into a project. Tasks may appear or disappear, others could be longer or shorter than forecast. This therefore impacts the notion of project planning. The specificities of the project context are: the notion of uniqueness (there is no recurrence in the projects), the notion of limited horizon (there are different milestones and contractual commitments), and the notion of a multi-expertise environment (numerous actors with different skills, perceptions and points of view are working together). Model of the system and its environment presented in previous section allows us to specify these notions. In this section we make the link between system modeling, project planning, project management and risk management. To our knowledge, few methods are able to do that. In 2006, we propose a reading grid of the risk management approaches following two families (Gourc 2006): the symptomatic approach and the analytic approach. The first one, called riskuncertainty, is associated with approaches where project risk management is transformed into project uncertainty management (Ward and Chapman 2003). The second approach family considers risk as an event that can affect achievement of the project objectives (Carter et al. 1996). The risk is described as an event, associated to an element of the system, which has occurrence characteristics (potentiality to occur) and consequence characteristics on the project objectives (impact in the event of occurrence). We propose to make the link between project management and risk management by analyzing the consequences of a risk "as an event" in the project. This work is also complemented with the integration of risk treatment strategies that can be often translated as new project planning tasks. This leads the project manager to use a synchronized process between risk management and the project schedule process.

\subsection{Project management approach integrating event procedure management}

Project management and risk management processes are generally presented as independent. Each process is described with precision but the interrelations, which may exist, are never shown. This hypothesis is overly simplistic and leads to improper decisions. Pingaud and Gourc (Pingaud and Gourc 2003) propose a project management approach based on a synchronized process of project schedule and risk management, presented in figure 3 .

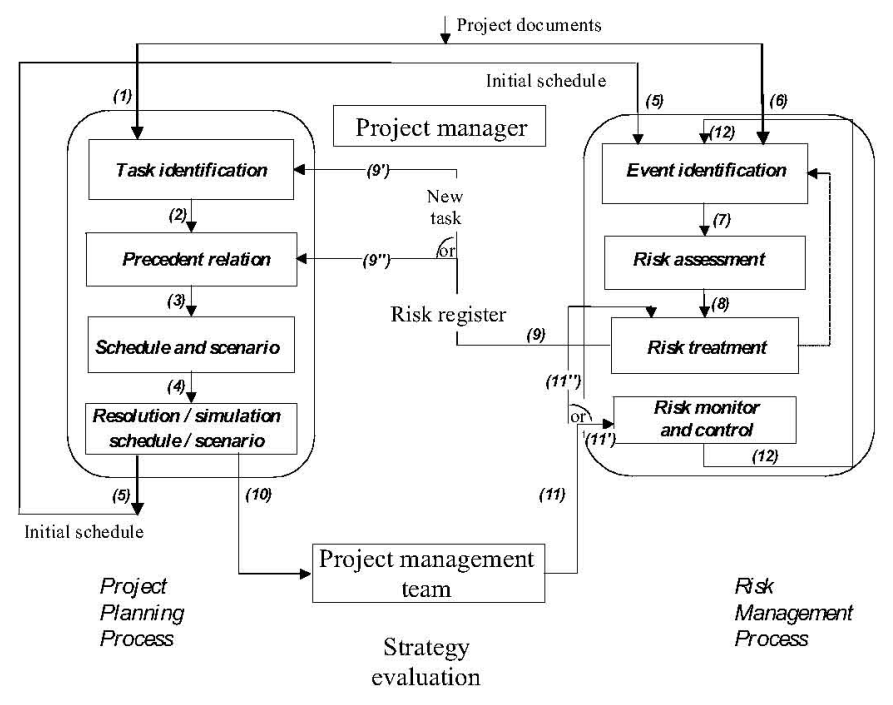

Fig. 3. Synchronization Process Model of Risk Management Process and Project Schedule Process

This synchronized process illustrates:

- the initial scheduling influence of a project on the identification and evaluation of the project risks (steps (5) and (6) in Fig. 3);

- the influence of planned treatment actions to reduce the risk on a project schedule.

The aims of the treatment actions are to either reduce the probability (from an initial probability to a reduced probability) and/or the impact (from an initial impact to a reduced impact). In this case, the authors refer to schedule with risk to indicate that the schedule takes into account the presence of risk in the project completion date evaluation and in the starting and completion date of each task (steps (9), $\left(9^{\prime}\right)$ and (9") in Fig. 3).

On the basis of these works, we developed a tool designed to help managers to choose the strategy suited to the risks and contractual conditions. This tool is mainly usable in two situations. First, faced with a known risk, it guides the project manager in the choice of a strategy that allows both budget and contractual deadline commitments to be respected. Secondly, when the sales department responds to an invitation to tender, the project manager can indicate if the proposed financial conditions and the defined deadline allow the different risks to be correctly integrated into the projected profitability and its realizability. Therefore, the objectives of the proposed model are to:

- determine the impacts of the identified risks on the schedule. The traditional approach sorts risks separately in order to determine which risk is the most critical. The proposed approach allows determination of which risk sub-set (or scenario) is the most critical; 
- determine the impacts of the treatment actions on the schedule (modification of the total duration, margin of each schedule task, reduction of the cost induced by unwanted events, modification of risk occurrence probabilities, etc.);

- help choose the best treatment strategy.

Our objective is to propose a complete framework, taking account of all disturbances generated by a risk. It should permit evaluation of its consequences on project management, particularly on the deadline dimension. In addition, this environment will be useful for managers, in order to measure the project global risk level, by taking into account the different possible scenarios, as well as helping to choose the most suitable risk strategies.

\subsection{Proposed model}

Taking decisions in the choice of a risk treatment strategy for a project is a multicriteria problem. However when the project manager has to take the decision, the number of criteria used to measure the impact of the proposal is most often reduced to the main ones: the probability of the scenario, the cost, which is a sensitive and finite resource, and the delay, which is traditional a matter of contractual commitment.

A project is described by its tasks $T_{t}(t=1 \ldots T), T$ being the number of project tasks. The planning process gives an initial planning Pi that doesn't integrate any risks. A project is also described by its set of identified risks $R_{i}(i=0 \ldots n)$, $n$ being the number of identified risks. Each $R_{i}$ is characterized via the risks management process. It has a probability and an impact. The initial impact allows consideration of the fact that the task is running in a graceful degradation. A risk $R_{i}$ is also characterized by its period of occurrence, i.e. the tasks during which the risk can occur.

A risk scenario $\mathrm{ScR}_{\mathrm{s}}$ corresponds to a combination of the risks that are considered as occurring. A project presenting $\mathbf{n}$ risks leads to $2 \mathrm{n}$ risks scenarios. Then $\operatorname{ScR}_{\mathrm{s}}(\mathrm{s}=1 \ldots 2 \mathrm{n})$ is a possible achievement with $\mathrm{k}$ risks $(0 \leq k \leq n)$ and the total number of risk scenarios, presenting $\mathbf{k}$ of the $\mathrm{n}$ identified risks, is equal to. Each risk can be treated in various ways that can be preventive, corrective or a combination of several actions. A risk $R_{i}$ can be associated to one or more treatment strategies $\operatorname{StT}_{i j}(\mathrm{j}=1 \ldots \mathrm{m}), \mathrm{m}$ being the number of identified strategies for $R_{i}$. A treatment strategy $S_{i j}$ groups a set of treatment actions $A_{i j \alpha}\left(\alpha=1 \ldots\right.$ a) to avoid or reduce the risk $R_{i}$, a being the number of identified treatment actions. A treatment action can be materialized by a task to achieve and it can introduce 3 types of modification to the WBS:

- addition of a new task, which generates a new action to realize;

- $\quad$ suppression of a task from the initial schedule. The risk is reduced by suppressing a task from the schedule;

- modification of an existing task that can be resumed by the suppression of a task and the addition of another one.
A treatment strategy is a preventive strategy if it contains at least a preventive treatment action. Otherwise, it is a corrective strategy. If the strategy consists in running no action at all, it is noted as being an empty set such as $\varnothing$.

Finally, for each risk $R_{i}$ several treatment strategies are possible. The definition of these strategies can lead to the appearance of treatment actions common to several risks. The set of all the identified $S t T_{i j}$ for a risk $R_{i}$ is written $S t R_{i}$.

A treatment scenario $\mathrm{ScT}_{\mathrm{d}}(\mathrm{d}=1 \ldots \mathrm{D})$ corresponds to a combination of the treatment strategies chosen to deal with the different risks of a project. The set of treatment scenarios is given by:

The probability and the impacts (delay and cost) are qualified of initial before the development of the risk management approach. They are qualified of reduced if they are modified after the achievement of the treatment actions.

Then, a project scenario $\mathrm{ScP}_{\mathrm{p}}(\mathrm{p}=1 \ldots \mathrm{P})$ is defined as being a possible project achievement that is built with a risk scenario and treatment scenario $\left.\left(\mathrm{ScP}_{\mathrm{p}}=<\mathrm{Pi}, \mathrm{ScR}_{\mathrm{s}}, \mathrm{ScT}_{\mathrm{d}}\right\rangle\right)$. The set of project scenarios ES is obtained by combining the set of occurring risks (or a risk scenario) and the set of determined treatment actions (or treatment scenario).

\subsection{Proposed new resolution approach: ProRisk}

To evaluate the different possible project scenarios, the management team needs to generate an initial schedule, without integrating the notions of risk and treatment. It then needs to calculate the different risk and treatment scenarios. These scenarios allow the set of the project scenarios to be constructed. Finally, when the project scenarios are known it is possible to obtain their durations and their costs (Nguyen 2013, Marmier 2013). Therefore, the proposed method uses data from the schedule process from the risk management process; as presented in figure 4 .

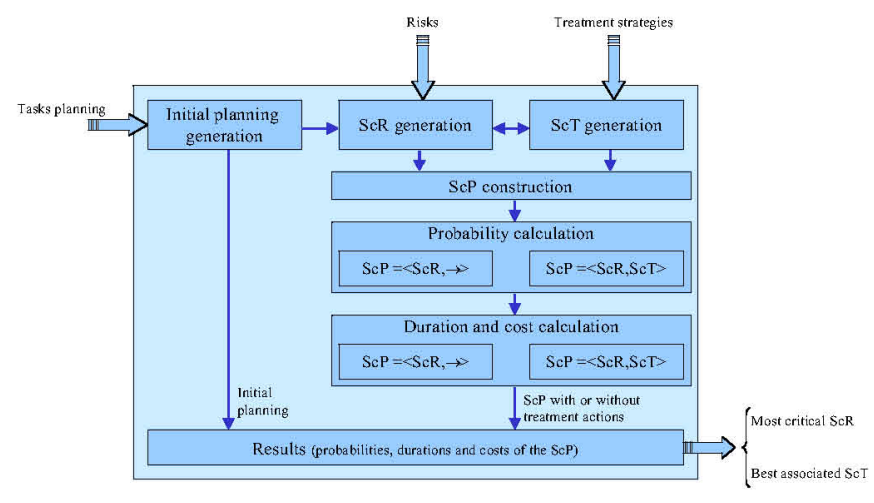

Fig. 4. ProRisk Main Modules.

ProRisk contains six modules:

- Initial schedule generation. The initial schedule generation allows the project schedule to be created by considering the whole project tasks, their precedence links and initial duration. The duration obtained is the total project duration that corresponds to the schedule, without taking into account the risks. 
- Risk scenarios generation. The module is the list of the different risks. The objective of the risk scenarios generation is to generate all possible risk sub-sets.

- Treatment scenarios generation. The different possible treatment strategies and the actions they contain to deal with each risk and their effects are introduced in this module. Treatment scenario generation consists in determining all possible treatment scenarios.

- Project scenarios construction. This module takes the different risks and project scenarios to generate the whole project scenario. The first iteration of the project scenario construction function lists possible scenarios with only one risk. The second iteration allows constructing a scenario by adding a second risk. Finally, we obtain the possible scenario total set by considering all the possible risks combinations.

- Probability calculation of each project scenario. The probability calculation method for each project scenario differs due to the fact that the project scenarios contain, or do not contain, a treatment strategy. It is not an objective of this module to determine whether a risk exists or not, or to evaluate its characteristics. However, during a project, using data relative to newly identified and quantified risks, the proposed approach permits progressive completion/modification of the set of project scenarios using the newly acquired knowledge.

- Duration and cost calculation of each project scenario. For each project scenario, the duration and the cost are calculated by taking into account potential modifications induced at the schedule level by the achievement of treatment strategies. The PERT method is used to calculate the project scenario duration. After having adapted the initial schedule in accordance with the studied scenario (modified duration, tasks added or removed), the project scenario duration is computed by taking into account the earliest starting dates.

This methodology and tool are flexible. That makes possible to obtain statistics before the project launching, as well as during the project lifecycle, by taking into account the current date and the state of the different risks and tasks.

\section{CASE STUDY}

To illustrate and validate our proposals, we propose an example taken from a case study on the construction of a weather forecast station. This project involves different business as earthwork, masonry, metal (mounting a mast / antenna wire), electronics, meteorology, etc.). Different actors of different sectors are involved in the project. Many project data were collected from participants in the project and particularly the project manager. At the end of our case study, results are discussed with the project manager and the scenarios are compared on the basis of their effectiveness.

\subsection{Presentation}

The project includes 10 phases, for a total of 42 tasks (T1 to T42). The initial planning gives a horizon of 180 UT (Unit of Time). In the context of our example, we will consider two risks that may occur during the development of the task of drilling and the assembly of the antenna (table 1). Different strategies to deal with these risks are studied (Tables 2 and 3). Two critical resources are considered (Table 4), they contribute to the achievement of certain tasks and are neither replaceable nor exchangeable.

The risk $\mathrm{R} 1$ described in table 1 corresponds to the premature wear of the head of the drill. If it is not replaced, the activity slowed. R2 is the risk of injury on site during installation of the metal structure of the antenna. Its initial impact is an increase in the charge of the other team members and therefore an extension of the task.

Table 1: Risks

\begin{tabular}{|l|l|l|l|l|}
\cline { 2 - 5 } \multicolumn{1}{c|}{} & Probability & $\begin{array}{l}\text { Period of } \\
\text { occurrence }\end{array}$ & $\begin{array}{l}\text { Initial impact time } \\
\text { (In UT) }\end{array}$ & \begin{tabular}{l} 
Treatment strategies \\
\hline $\mathrm{R}_{1}$
\end{tabular} \\
\hline $30 \%$ & $\begin{array}{l}\text { Core drilling } \\
\text { of the area }\end{array}$ & 15 & $\begin{array}{l}\mathrm{StT}_{11}-\text { Develop a maintenance plan for the core drill after the start of the project } \\
\mathrm{StT}_{12}-\text { Repair the core drill } \\
\mathrm{StT}_{13}-\text { Rent another } \\
\mathrm{StT}_{14}-\text { Establish a maintenance plan and rent if occurrence }\end{array}$ \\
\hline $\mathrm{R}_{2}$ & $20 \%$ & $\begin{array}{l}\text { Assembly of } \\
\text { the structure }\end{array}$ & 5 & $\begin{array}{l}\mathrm{StT}_{21}-\text { Replace an actor of the company } \\
\mathrm{StT}_{22}-\text { Recruit a tempory }\end{array}$ \\
\hline
\end{tabular}

Table 2: Treatment strategies

\begin{tabular}{|l|l|l|l|l|}
\cline { 2 - 5 } \multicolumn{1}{c|}{} & Type of strategy & Action/task & Reduced probability & Modified task \\
\hline $\mathrm{StT}_{11}$ & Preventive & $\mathrm{A}_{111}-$ Perform regular maintenance & $20 \%$ & Core drilling of the area \\
\hline $\mathrm{StT}_{12}$ & Corrective & $\mathrm{A}_{121}-$ Make repair the core drill & Core drilling of the area \\
\hline $\mathrm{StT}_{13}$ & Corrective & $\mathrm{A}_{131}-$ Assign another core drill & Core drilling of the area \\
\hline $\mathrm{StT}_{14}$ & Preventive & $\begin{array}{l}\mathrm{A}_{141}-\text { Perform regular maintenance } \\
\mathrm{A}_{142}-\text { Assign another core drill }\end{array}$ & $20 \%$ & Core drilling of the area \\
\hline $\mathrm{StT}_{21}$ & Corrective & $\mathrm{A}_{211}-$ Review schedules and assign an actor & Assembly of the structure \\
\hline $\mathrm{StT}_{22}$ & Corrective & $\mathrm{A}_{221}-$ Start the recruitment of an interim & Assembly of the structure \\
\hline
\end{tabular}


Table 3: Treatment actions

\begin{tabular}{|c|c|c|c|c|}
\hline & Predecessors & Successors & $\begin{array}{l}\text { Duration } \\
(\mathrm{UT})\end{array}$ & $\begin{array}{l}\text { Fixed cost } \\
(\mathrm{UM})\end{array}$ \\
\hline $\mathrm{A}_{111}$ & Delineate the area & Prepare the core & 1 & 4 \\
\hline $\mathrm{A}_{121}$ & Core drilling of the area & Study carrots & 1 & 4 \\
\hline $\mathrm{A}_{131}$ & Core drilling of the area & Study carrots & 0.2 & 24 \\
\hline $\mathrm{A}_{141}$ & Delineate the area & Prepare the core & 1 & 4 \\
\hline $\mathrm{A}_{142}$ & Core drilling of the area & Study carrots & 0.2 & 24 \\
\hline $\mathrm{A}_{211}$ & Assembly of the structure & Equipping the structure & 0.2 & 4 \\
\hline $\mathrm{A}_{221}$ & Assembly of the structure & Equipping the structure & 1 & 8 \\
\hline
\end{tabular}

Table 4: The critical resources

\begin{tabular}{|l|l|l|l|}
\cline { 2 - 3 } \multicolumn{1}{c|}{} & Tasks requiring the CR & $\begin{array}{l}\text { Beginning of the availability } \\
\text { period }\end{array}$ & $\begin{array}{l}\text { Duration of the } \\
\text { availability (UT) }\end{array}$ \\
\hline Drum & Make the basement of the structure & $\mathrm{t}_{0}$ & 25 \\
\hline Steamroller & Steam the access & $\mathrm{t}_{0}$ & 13 \\
\hline
\end{tabular}

\subsection{Presentation of the results}

Table 5 shows the different project scenarios possible in this study. It is possible from this table to assess the relevance of the implementation of each corrective strategy for each risk scenario in terms of criticality. Criticality of zero means that the project complies with contractual commitments. Probability and impacts on duration and cost are identified.

Table 5: Set of project scenarios

\begin{tabular}{|c|c|c|c|c|c|}
\hline $\mathrm{N}^{\circ} \mathrm{ScP}$ & Probability & Couple (Risk,Strategy) & Duration (UT) & Cost (UM) & Criticality \\
\hline 1 & 0,64 & (.,ST11) & 183 & 4 & 0,000 \\
\hline 2 & 0,56 & & 180 & 0 & 0,000 \\
\hline 3 & 0,24 & $(\mathrm{R} 1,)$. & 195 & 0 & 0,000 \\
\hline 4 & 0,24 & (R1,StT12) & 185 & 4 & 0,000 \\
\hline 5 & 0,24 & (R1,StT13) & 181 & 24 & 0,000 \\
\hline 6 & 0,16 & (R1,ST11) & 183 & 4 & 0,000 \\
\hline 7 & 0,16 & (R1,StT14) & 186 & 28 & 0,022 \\
\hline 8 & 0,16 & $(., \mathrm{ST} 11)(\mathrm{R} 2,)$. & 193 & 4 & 0,000 \\
\hline 9 & 0,16 & (.,ST11) (R2,StT21) & 183 & 8 & 0,000 \\
\hline 10 & 0,16 & $(., \mathrm{ST} 11)(\mathrm{R} 2, \mathrm{StT} 22)$ & 183 & 12 & 0,000 \\
\hline 11 & 0,14 & $(\mathrm{R} 2,)$. & 190 & 0 & 0,000 \\
\hline 12 & 0,14 & (R2,StT21) & 180 & 4 & 0,000 \\
\hline 13 & 0,14 & (R2,StT22) & 180 & 8 & 0,000 \\
\hline 14 & 0,06 & $(\mathrm{R} 1,).(\mathrm{R} 2,)$. & 205 & 0 & 0,030 \\
\hline 15 & 0,06 & $(\mathrm{R} 1,).(\mathrm{R} 2, \mathrm{StT} 21)$ & 195 & 4 & 0,000 \\
\hline 16 & 0,06 & $(\mathrm{R} 1,).(\mathrm{R} 2, \mathrm{StT} 22)$ & 195 & 8 & 0,000 \\
\hline 17 & 0,06 & $(\mathrm{R} 1, \mathrm{StT} 12)(\mathrm{R} 2,)$. & 195 & 4 & 0,000 \\
\hline 18 & 0,06 & (R1,StT12) (R2,StT21) & 185 & 8 & 0,000 \\
\hline 19 & 0,06 & (R1,StT12) (R2,StT22) & 185 & 12 & 0,000 \\
\hline 20 & 0,06 & $(\mathrm{R} 1, \mathrm{StT} 13)(\mathrm{R} 2,)$. & 191 & 24 & 0,000 \\
\hline 21 & 0,06 & (R1,StT13) (R2,StT21) & 181 & 28 & 0,008 \\
\hline 22 & 0,06 & (R1,StT13) (R2,StT22) & 181 & 32 & 0,019 \\
\hline 23 & 0,04 & $(\mathrm{R} 1, \mathrm{ST} 11)(\mathrm{R} 2,)$. & 193 & 4 & 0,000 \\
\hline 24 & 0,04 & (R1,ST11) (R2,StT21) & 183 & 8 & 0,000 \\
\hline 25 & 0,04 & (R1,ST11) (R2,StT22) & 183 & 12 & 0,000 \\
\hline 26 & 0,04 & $(\mathrm{R} 1, \mathrm{StT} 14)(\mathrm{R} 2,)$. & 196 & 28 & 0,007 \\
\hline 27 & 0,04 & (R1,StT14) (R2,StT21) & 186 & 32 & 0,013 \\
\hline 28 & 0,04 & (R1,StT14) (R2,StT22) & 186 & 36 & 0,020 \\
\hline
\end{tabular}

\subsection{Analysis of possible decisions}

The objective of this research work is to give decision makers a methodological tool to compare the impact of risks and their treatment on the project, but also to have a light on the feasibility with regard on the availability of critical resources. The proposed approach permits evaluate the relevance of corrective treatments of risk, this whatever the context of preventive treatment implemented. Knowing which corrective treatment will be decided in all possible cases, it is possible to decide what would be the best possible preventive treatment strategy. For each scenario, information about the feasibility is given. In a first approach it is possible to know whether the schedule is feasible with the availability granted by the organization. If it doesn't correspond, the project manager can specify the dates where critical resources are needed. If all its resources are already preempted for other projects over the periods of requirement, negotiation can be started with the business manager. If the business manager offers different resources with different ranges of availability, the PM can select those that can best ensure the progress of the tasks for which they would be in charge knowing the potential occurrence of risks. 
The example is deliberately simple for the demonstration purposes, but the behavior of the proposed approach can be extrapolated to wider problems and situations more representative of actual project.

Risks do not relate directly to critical resources. But the impact of these risks can modify the period of critical resources requirement. Risks relating to resources are then transferred on the tasks, within the framework of this approach.

\section{CONCLUSIONS}

The choice of the best strategy for dealing with the risks of a project is often difficult. When the project aims to deliver a product with technological innovations, specific resources may be required. Resources with particular characteristics are often limited in organizations. It becomes necessary to ensure that they will be available at the right time and will be used when available. We propose an approach to model and assess the impact of risks on the duration and cost of the project. This approach uses the principles of the synchronized project planning and risk management. It is based on the concepts of risk scenario, risk treatment scenario and project scenario to characterize and evaluate the effects of risks on the project. This method evaluates the overall level of risk and selects the best risk treatment strategy while analyzing the feasibility. An estimate of the overall risk of the project gives an overview of possible scenarios. We illustrate the principles of our approach through a case study and a software tool has been developed.

It is often difficult to compare criteria antagonists such as compliance with contractual commitments and resource overload. The first perspective of this work is to facilitate the integration of the resource overload in the other two criteria (cost and duration). Given that different actors may be required for specific tasks, the second perspective of this research is to examine the influence of the skills required in the project in the model.

\section{REFERENCES}

Boztepe S. (2007). Toward a framework of product development for global markets: a user-value-based approach. Design Studies, vol.28-5, 513-533.

Carter B., Hancock T., Morin J., Robin N. (1996). Introducing RISKMAN: the European project risk management methodology. The Stationery Office.

Chang D.R. and Cho H. (2008). Organizational memory influences new product success. Journal of Business Research, vol. 61, 13-23.

Chen H.H., Kang H.Y, Xing X., Lee A.H.I and Tong Y. (2008). Developing new products with knowledge management methods and process development management in a network. Computers in Industry, vol. 59, 242- 253

Chen, C. J., and Huang, J. W. (2009). Strategic human resource practices and innovation performance - the mediating role of knowledge management capacity. Journal of Business Research, vol. 62,104-114.
Girard Ph., Doumeingts G. (2004). Modelling of the engineering design system to improve performance, Computers \& Industrial Engineering, Vol. 46-1, 43-67.

Girard P. and Robin V. (2006). Analysis of collaboration for project design management. Computers in Industry, vol. 57(8-9), 817-826.

Gonnet S., Henning G. and Leone H. (2007). A model for capturing and representing the engineering design process. Expert Systems with Applications, vol. 33, 881902.

Gourc D. (2006). Towards a general risk model for piloting goods- and service-related activities. $H D R$ de l'Institut National Polytechnique de Toulouse, France.

Hicks B.J., Culley S.J., Allen R.D. and Mullineux G. (2002). A framework for the requirements of capturing, storing and reusing information and knowledge in engineering design. International Journal of Information Management. vol. 22, 263-280.

Marmier F., Gourc D. and Laarz F. (2013). A risk oriented model to assess strategic decisions in new product development projects. Decision Support Systems. doi: 10.1016/j.dss.2013.05.002.

Nguyen T.H., Marmier F. and Gourc D. (2013). A decisionmaking tool to maximize chances of meeting project commitments. International Journal of Production Economics. vol. 142, $\mathrm{n}^{\circ} 2,214-224$.

Patanakul P. and Milosevic D. (2008). A competency model for effectiveness in managing multiple projects. Journal of High Technology Management Research. Vol. 18-2, 118-131.

Pingaud H. and Gourc D. (2003). Approach of controlling an industrial project by the risk analysis. $5^{\text {ième } \text { Congrès }}$ International de Génie Industriel, Québec, Canada.

Robin V., Merlo C., Pol G. and Girard P. (2010). Management of design system in a collaborative design environment thanks to PEGASE. $I^{\text {st }}$ International Conference on Modelling and Management of Engineering Processes, MMEP 2010, Cambridge University, United Kingdom, 2010.

Sperandio S., Pereyrol F., Bourrieres J.P. (2004). Production system life-cycle for control assessment. IEEE Conference on Systems, Man and Cybernetics, SMC'04, The Hague, The Netherlands.

Sperandio S., Robin V. and Girard Ph. (2007). Towards an integrated management of engineering design system and enterprise. Proceedings of the International Conference on Engineering Design, ICED07, Paris, France.

Vernadat F.B. (1996). Enterprise Modelling and Integration: Principles and Applications. Chapman \& Hall, London.

Ward, S. and Chapman, C. (2003). Transforming project risk management into project uncertainty management. International Journal of Project Management, vol. 21-2, 97-105.

Yang H.L. and Wu T.C.T. Knowledge sharing in an organization. Technological Forecasting and Social Change, vol. 75-8, 1128-1156. 